\title{
O rigens, influências e aplicações das medicinas asiáticas no mundo globalizado
}

ALTER, Joseph S. (Ed.).

Asian M edicineand G lobalization (Encounters with Asia).

Philadelphia: University of Pennsylvania Press, 2005. 187 p.

| 'Pamela Siegel, ${ }^{2}$ Nelson Filice Barros |

${ }^{1}$ Laboratório de Práticas Alternativas Complementares e Integrativas em Saúde (Lapacis); DMPS/FCM/UNICAMP. Endereço eletrônico: pam@mpcnet.com.br.

${ }^{2}$ Laboratório de Práticas Alternativas Complementares e Integrativas em Saúde (Lapacis); DMPS/FCM/UNICAMP. Endereço eletrônico: nelfel@uol.com.br.

O livro Asian M edicineand G lobalization [M edicinasAsiáticase G lobalização] é constituído da introdução considerada capítulo primeiro e outros oito capítulos. A introdução e o segundo capítulo são escritos por Joseph Alter, antropólogo, professor da Universidade de Pittsburgh e organizador do livro, e os demais, sobre vários temas relacionados à medicina asiática eà globalização, são redigidos por diferentes autores.

$\mathrm{N}$ a Introdução, Alter ilustra a maneira como as formas de medicina asiáticas tendem a estar ligadas, na prática e na imaginação, a nações específicas, como Índia, C hina, Inglaterra, Estados U nidos, etambém Austrália, Tibet, Cingapura e Alemanha. Para o autor, o resgate da história de uma nação estaria firmemente travestido de um nacionalismo que orienta a construção particular da história, embora esta seja definida como objetiva e desinteressada. Ele aborda a questão do status do Ayurveda ou da M edicina Tradicional Chinesa (M TC) como sistemas médicos, tema ricamenteestudado no Brasil com as racionalidadesmédicas, conceito elaborado por Luz (1988) e muito atual para a Saúde Coletiva nacional, dada a publicação da Política N acional dePráticas I ntegrativas eC omplementares (PN PIC) em maio de 2006 (M ARQUES, 2003; BARROS et al., 2007).

No segundo capítulo, "Acupuntura Ayurvédica - nacionalismo transnacional: ambivalência sobre a origem e autenticidade do conhecimento médico", Alter explica como as ideias sobre fisiologia, anatomia, terapia e diagnóstico se moviam ao longo das rotas comerciais, tanto marítimas como terrestres, e entre os centros 
de saber einstituições religiosas local izadas ao longo destas rotas, durante os séculos III e VIII. Toma a afirmação feita em 1982 pelo D r. Ashima Chatterjee, de que acupuntura não fora inventada na C hina, mas nascida na forma da acupressão na Índia, e comenta que tentar equiparar os pontos da acupuntura com os pontos vitais indianos causa grande confusão. Conclui afirmando que o debate sobre a eficiência de uma medicina, bem como sobre a delimitação de um sistema médico, éinfinita, pois são estas questões que recebem uma moldura nacionalista e política da cultura, gerando fronteiras intelectuais e políticas porosas.

N o capítul o terceiro, "Ares desviantes na medicina 'tradicional' chinesa", as autoras Vivienne Lo eSylviaSchroer estudam o termo xieda medicina chinesa, cujo significado é al go que desvia do padrão, que é vazio de retidão, em oposição ao qi, a energia curadora queflui pelo organismo. I deias médicas sobre possessão demoníaca einvasão de entidades associadas com condições climáticas foram agrupadas sob a rubrica de xie zhu (aquilo que flui para dentro de), na antiga literatura chinesa. As autoras buscaram entender como o termo xie tem sido usado na prática contemporânea europeia da medicina asiática e, para isto, entrevistaram 15 praticantes europeus de medicina chinesa. Puderam constatar que o aprendizado e a prática da medicina chinesa após 1950 excluem o conceito de xie como espírito maligno ou fantasma, substituindo-o simplesmente por "invasão por vento ou umidade", intoxicação, redução da imunidade, invasão de patógenos externos que "entopem os canais".

A. I rfan $\mathrm{H}$ abib e D hruv Raina analisam no capítulo quarto, "R einventando a medicina tradicional: método, mudança institucional e a manufatura de medicamentosna Índia colonial tardia", a transformação da prática das medicinas Ayurvédica e U nani nos séculos XIX e XX. A partir da percepção do declínio do Ayurveda como ciência e da maneira como o mecanismo da transferência oral do conhecimento criou uma barreira à multiplicação da expertise, surgiu a necessidade de instituir um sistema novo de manufatura, distribuição e padronização da qualidade da medicação usada. Apesar desta transformação, tanto os hindus ultranacionalistas como a historiografia colonialista deixam a imagem de que a ciência indiana criou resistências à influência estrangeira, muito embora 0 pragmatismo do curandei ro tradicional tenha sido transformado no dogmatismo da medicina tradicional contemporânea.

O quinto capítulo, "Saúde e medicina na Índia Britânica e H olandesa: um estudo comparado", de autoria de D eepak Kumar, abrange a saúde e a doença nas 
colônias britânicas e holandesas, contextualizando a época das grandes navegações elembrando que durante os séculos XVII eXVIII, todos os navios da Companhia das Índias tinham um cirurgião-naturalista a bordo. N o século XX, a Fundação Rockefeller exerceria importante papel na Ásia, criando uma consciência médicotécnica na C hina e na Índia, ao subsidiar várias pesquisas na área da saúde, para se tentar evitar o adoecimento da mão-de-obra que trabalhava nas plantações. As vozes autóctones dos praticantes da medicina U nani se fizeram ouvir, mas somente a partir de 1930 a "indianização" dos serviços médicos foi implantada.

"N acional ismo, transnacionalismo ea política da medicina 'tradicional' indiana para H IV/Aids" é o sexto capítulo do livro, no qual Cecília Van H ollen examina o papel complexo e desigual que o discurso nacionalista exerce no contexto do fluxo transnacional da medicina tradicional indiana, demonstrando que o caráter "social" desta "medicina tradicional" está sendo redefinido no século XXI . A autora analisa o fato de o Ayurveda ter-se tornado um poderoso símbolo da identidade nacionalista indiana e da resistência à ocidentalização, ilustrado pelo manifesto $\mathrm{H}$ ind Swaraj (Indian H ome Rule) de G andhi, escrito em 1908, em queele desafia frontalmenteo valor da prática biomédica. O utro enfoque da autora é sobre o tratamento de portadores deH IV/AidsnaÍndia com ervas derivadas dossistemas Ayurveda, Siddha, Unani e Homeopatia, sobretudo a partir dos anos 1990, quando o indiano T.A. $M$ ajeed ficou célebre ao criar um tratamento que combinava mais de 20 ervas, cuja fórmula ele chamou de ImmunoQ R. Relata, por um lado, que em meio a várias polêmicas, durante as quais al guns médicos da África do Sul e dosU SA tinham boa aceitação do IQ R em seuspacientes e reclamavam dos empecilhoslegais para importar o produto, M ajeed teve caçada sua licença para a fabricação do medicamento. Por outro, os discursosnacionalistasindianos construíram uma dicotomia entreo caseiro/ mundano e entre a espiritualidade/materialismo, de forma que defensores do tratamento médico tradicional paraH IV/Aids condenavam as corporações biomédicas multinacionais e, ao mesmo tempo, demonstravam os méritos de sua própria medicina, baseados no sucesso financeiro e penetração global de seus produtos.

No capítulo sétimo, "M apeamento de ciência e nação na C hina", N ancy N . Chen mostra como a ciência foi usada para articular agendas nacionais e definir fronteiras da medicina chinesa contemporânea. D urantea última década, o qi gong circulou em contextostransnacionais como umaforma decura "tradicional" chinesa, porém dentro da China certos tipos de qigong eram contemplados como 
supersticiosos ou patológicos, enquanto que as formas científicas eram mais aceitáveis. N o período pós-maoísta, a partir da C onferência N acional de Ciência, em 1978, físicos foram envolvidos na pesquisa empírica para testar o fenômeno qi. Publicaçõesem periódicos como $\mathrm{N}$ aturetentaram estabelecer o qi como um elemento físico, similar às partículas-ondas. Versões medicalizadas e seculares do qigong, chamado o qigong médico, que reduziam os efeitos alucinatórios e removiam a necessidade de mestres carismáticos, foram introduzidas estrategicamente, promovendo a supervisão de médicos e praticantes registrados. A autora observa que, ao mapear as formas em que a ciência é invocada, podemos traçar como os discursos científicos não só mantêm classificações de conhecimento autêntico ou pseudociência, como também compreender como estes são fundamentais para a formação dos sujeitos-cidadãos modernos.

Em seguida, no oitavo capítulo, "G inecologias sânscritas na pós-modernidade: a 'commoditização' da medicina indiana em discursos médicos alternativos e de new-age sobre saúde da mulher", M arthaAnn Selby examina como defensores das medicinas euro-americana, new age ealternativa transformaram ideias ayurvédicas sobre a saúde da mulher num segmento essencial einfluente da indústria do bemestar pós-moderno. Ela parte do estudo, em sânscrito, dos dois textos mais relevantes do Ayurveda: o Caraka Samhita (século II) e o Susruta Samita (século III), e os compara com as traduções para o inglês. I dentifica passagens dúbias nos textos modernos ea supressão de parágrafos inteiros, principalmente aquelesquese referem a detalhes eróticos, evadindo, assim, a temática da dinâmica sexual e formulando regimes de bem-estar para mulheres, os quais ocultariam elementos patriarcais, hierárquicos e até misógenos. Assim, conclui a autora que a maioria dos livros modernos sobre Ayurveda se enquadraria no gênero de autoajuda e as práticas orientais estariam se transformando em commodities ocidentais para o consumo feminino, invertendo os ideais do Ayurveda clássico.

N o nono eúltimo capítulo, "C hina reconstrói: cirurgia cosmética enacionalismo na Era da Reforma", Susan Brownell descreve o percurso transnacional inverso da cirurgia plástica e como ela foi apropriada pelas práticas chinesas. A partir de 1980, as práticas da cirurgia cosmética foram adotadas pela China, tanto por cirurgiões plásticos que vincularam suas habilidades com afirmações de patriotismo nacionalista, como por pacientes, cujos desejos criaram um mercado para procedimentos cosméticos, especialmente a cirurgia de pálpebra. A partir da 
Segunda Guerra M undial, os asiáticos começaram a solicitar cirurgia plástica de pálpebra e implantes nasais, primeiramente na Ásia e depois nos U SA. A prática, que fora denunciada como sendo burguesa por privilegiar a forma mais do que a função, recebeu uma grande demanda a partir da abertura da China nos anos 1990, quando seacentuou o intercâmbio sino-americano. A apropriação histórica da cirurgia cosmética foi tal que nas introduções dos livros didáticos da medicina chinesa constam afirmações de que, na $C$ hina, ela remontaria à época do uso do rouge na dinastia Shang. A autora afirma que em 2001 o Badachu Plastic Surgery H ospital se tornou o maior hospital de cirurgia plástica do mundo e conclui discutindo a relação entre o "rosto" político da China e as "faces" das pessoas comuns, com implicações dos significados atribuídos a ambos.

O livro organizado por Joseph Alter resgata muito bem alguns elementos históricos das medicinas asiáticas, oferecendo uma visão crítica sobre as fronteiras políticas e culturais das mesmas. $\mathrm{N}$ o entanto, o que mais se pode depreender em relação ao nacionalismo etransnacionalismo dos sistemas médicoséa complexidade de se estabelecer uma hierarquia de eficiência e um "padrão ouro". Assim, concluise que uma das necessidades mais prementes para o campo da saúde na atualidade é 0 estabelecimento de um pluralismo de sistemas médicos, com suas múltiplas abordagens da saúde, da doença e do cuidado.

\section{Referências}

BARROS, N F.; SIEGEL, P.; SIMONI, C. Política Nacional de Práticas Integrativas e Complementaresno SU S: passos para o pluralismo na saúde. Cad. SaúdePública, Rio deJ aneiro, v. 23, n. 12, 2007. Disponível em: http://www.scielo.br/scielo.php?script=sci_arttext\& pid=S0102$311 \times 2007001200030 \&$ Ing=en\& nrm=ंso

LUZ, M . T. N atural, racional, social: razão médica eracionalidade científica moderna. São Paulo: Campos, 1988.

M ARQ UES, E. A. Racionalidades M édicas. medicina ayurvédica - tradicional arte de curar da Índia. Rio deJ aneiro: IM S/U ERJ, 1993 (SérieE sudosem SaúdeC oletiva n. 75). 